\title{
Erratum
}

\section{Rapid declines in habitat quality and population size of the Liben (Sidamo) Lark Heteromirafra sidamoensis necessitate immediate conservation action - ERRATUM}

\author{
PAUL F. DONALD, GRAEME M. BUCHANAN, NIGEL J. COLLAR, \\ YILMA DELLELEGN ABEBE, MERID N. GABREMICHAEL, \\ M. A. KIRAGU MWANGI, PAUL KARIUKI NDANG'ANG'A, \\ CLAIRE N. SPOTTISWOODE and MENGISTU WONDAFRASH
}

doi: 10.1017/S0959270910000018 Published by Cambridge University Press, 27 Jan 2010

Figure 5 of the above paper (Donald et al., 2010) was printed in black and white rather than colour. The publishers apologise for this error, and have reprinted the image below correctly.

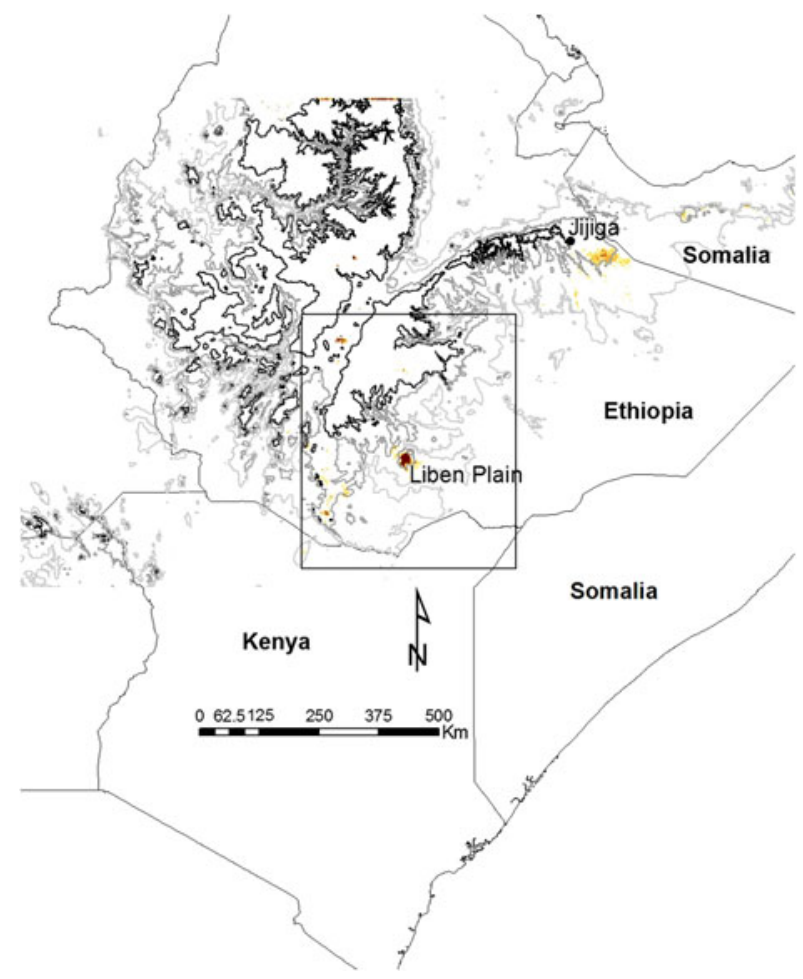

\section{Reference}

Donald, P. F., Buchanan, G. M., Collar, N. J., et al. (2010) Rapid declines in habitat quality and population size of the Liben (Sidamo)
Lark Heteromirafra sidamoensis necessitate immediate conservation action. Bird Conserv. Int. 20: 1-12. 